\title{
Positioning error and expanding margins of planning target volume with kilovoltage cone beam computed tomography for prostate cancer radiotherapy
}

This article was published in the following Dove Press journal:

OncoTargets and Therapy

\section{Gang Wang \\ Wen-Ling Wang \\ Yi-Qun Liu \\ Hong-Min Dong \\ Yin-Xiang $\mathrm{Hu}$}

Department of Abdominal Oncology, Affiliated Hospital of Guizhou Medical University, Guizhou Cancer Hospital, Guiyang, People's Republic of China
Correspondence: Wen-Ling Wang Department of Abdominal Oncology, Affiliated Hospital of Guizhou Medical University, Guizhou Cancer Hospital, I West Beijing Road, Yuyan District, Guiyang 550004, People's Republic of China

Tel +86 I 3885077539

Fax +8685 I 6740793

Email wenlingwangdoc@163.com

\begin{abstract}
Objective: In this study, prostate cancer patients were treated with image-guided radiotherapy (IGRT). The translational positioning errors were discussed to provide the basis for determining margins of the planning target volume (PTV).

Methods: Thirty prostate cancer patients were treated with radical radiotherapy using the IGRT system. Patients were placed in the supine position and underwent kilovoltage cone beam computed tomography (KVCBCT) scans before radiotherapy. A total of 447 images were acquired. The translational positioning errors were obtained in three linear directions which were X (left-to-right), Y (superior-to-inferior) and Z (anterior-to-posterior) axes (denoted as Lx, Ly and Lz) through the contrast between images adjusted with gray and manual registrations and the planning CT images. Rotational errors were denoted as $\mathrm{Rx}$, Ry and Rz.
\end{abstract}

Results: Uncorrected translational errors Lx, Ly and Lz in the 251 positioning images were all higher than those after correction, and the differences were all statistically significant $(P=0.000$, 0.037 and 0.004 , respectively). For rotational errors Rx, Ry and Rz, only Rx had a significant difference before and after correction $(P=0.044)$. Before correction, PTV margins in the X, Y and $\mathrm{Z}$ directions were $0.61,0.78$ and $0.41 \mathrm{~cm}$, respectively; after correction, these were 0.17 , 0.12 and $0.17 \mathrm{~cm}$, respectively.

Conclusion: KVCBCT can be applied to measure positioning errors in prostate cancer radiotherapy and correct these errors in real time through the $6^{\circ}$ robotic patient positioning system, in order to improve patient positioning accuracy. The application of IGRT with KVCBCT may reduce PTV margins.

Keywords: prostate cancer, image-guided radiotherapy, kilovoltage cone beam CT, positioning error, planning target volume

\section{Introduction}

Radiotherapy is one of the radical treatments for prostate cancer. In recent years, with the development of intensity-modulated radiation therapy, the dose and effect of radiotherapy for prostate cancer have been further improved. Accurate radiotherapy technology requires the reduction of the influence of positioning errors. However, positioning error remains as one of the obstacles in further improving the accuracy of treatment. External error size is an important factor of clinical target volume (CTV)to-planning target volume $(\mathrm{PTV})$ margins $\left(\mathrm{M}_{\mathrm{PTV}}\right)$ in radiotherapy. At present, $\mathrm{M}_{\mathrm{PTV}}$ is usually $10 \mathrm{~mm}$ in the absence of corrective measures. ${ }^{1}$ 
In recent years, with the extensive use of image-guided radiotherapy (IGRT) technology in clinics, related clinical studies have revealed significant differences in positioning errors in different directions. ${ }^{2}$ The rate of error for $\geq 6 \mathrm{~mm}$ in the anterior-to-posterior direction was $42 \%$, and the rates were $17 \%$ and $22 \%$ in the upper-to-lower and rightto-left directions. In addition, Palombarini et $\mathrm{al}^{3}$ revealed that in IGRT treatment for prostate cancer patients, except the backward direction, margins in other directions were significantly reduced. Based on significant differences in positioning errors in different directions and the significant reduction of positioning errors on the basis of the application of IGRT, ${ }^{3}$ it remains to be determined whether it is reasonable to uniformly expand the CTV-to-PTV margins in all directions by $10 \mathrm{~mm}$ in the radical radiotherapy for prostate cancer. This is a question that is worth discussing.

To further determine the reasonable expanding range of CTV-to-PTV margins in IGRT treatment for prostate cancer, the Department of Abdominal Tumor in our hospital adopted kilovoltage cone beam computed tomography (KVCBCT)-guided three-dimensional conformal intensitymodulated radiotherapy to treat 30 prostate cancer patients using the Elekta Synergy System. At the same time, the expanding margins were calculated according to the formula for $\mathrm{M}_{\mathrm{PTV}}\left(\mathrm{M}_{\mathrm{PTV}}=2.5 \Sigma+0.7 \delta\right)$ and through positioning errors before and after correction, to provide a theoretical basis for clinically determining reasonable expanding margins. ${ }^{4}$

\section{Patients and methods}

\section{General information}

Data of 30 prostate cancer patients, who underwent radical radiotherapy in the Department of Peritoneal Tumor of the Cancer Hospital of Guizhou Province from April 2012 to December 2015, were collected. Sample supplementary clinical data are as follows: the median age of these patients was 74 years (52-85 years), and the median Gleason score was 7 points (5-10 points). Before treatment, the median level of prostatespecific antigen was $14.23 \mathrm{ng} / \mathrm{mL}(9.37-259.20 \mathrm{ng} / \mathrm{mL})$. The pathological types were all adenocarcinomas. Staging was carried out according to the 7th edition of the American Joint Committee on Cancer (AJCC) staging in 2010: 11 cases were Stage II, 17 cases were Stage III and two cases were Stage IV. This study was conducted in accordance with the Declaration of Helsinki. This study was approved by the ethics committee of Guizhou Cancer Hospital. Written informed consent was obtained from all participants.

\section{CT simulation positioning}

Patients were placed in the supine position and fixed on the frame composed of thermoplastic film. Each patient underwent CT scans with a thickness of $5 \mathrm{~mm}$, when the rectum was empty and the bladder was fully filled. The acquired images were used for the outline of the radiotherapy target area and the design of the radiotherapy program, as well as in planning $\mathrm{CT}$ images in a rectangular coordinate system, in which the centers were also the tumor centers.

\section{Acquisition of KVCBCT images and positioning errors}

Patients were placed in a position and status the same as that used during the simulation positioning. Before each treatment, KVCBCT scanning started from $180.1^{\circ}$ and ended at $180^{\circ}$. Hence, a $359.9^{\circ}$ scan was completed to obtain the pretreatment KVCBCT image.

By matching the pretreatment KVCBCT images with the planning $\mathrm{CT}$ images, translational positioning errors in the $\mathrm{X}$ (left-to-right), Y (superior-to-inferior) and Z (anterior-to-posterior) axes (denoted as Lx, Ly and Lz) and rotational errors $\mathrm{Rx}, \mathrm{Ry}$ and $\mathrm{Rz}$ (with central axes located at the $\mathrm{X}, \mathrm{Y}$ and $\mathrm{Z}$ axes, respectively) were acquired. Correction standard was set at a translational error of $<3 \mathrm{~mm}$ and a rotational error of $<2^{\circ}$. When errors exceeded the correction standard, the position was corrected by a $6^{\circ}$ robotic patient positioning system. After correction, the aforementioned procedures were repeated to acquire the posttreatment KVCBCT images. Then, the corrected positioning errors were obtained by comparing these images with the planning CT images. Treatment was carried out until the errors met the standard. Pre- and posttreatment KVCBCT images were matched with the planning CT images using gray and manual registrations: $\mathrm{KVCBCT}$ images and planning CT images were concentrically matched using the gray registration pattern provided by the IGRT system. Then, the anatomical structure that inosculated best between the two kinds of images in three dimensions was determined. If the inosculation was not satisfied, manual adjustments were performed until maximum inosculation was achieved. The whole setup procedure is shown in Figure 1.

\section{Calculation of CTV-to-PTV margins}

The systemic error of positioning for each patient was expressed as the average value $(\bar{x})$ of all positioning errors for this patient, while random error was expressed as the SD of all positioning errors of this patient. Total systematic error was expressed as the average value of systematic errors in all patients (denoted as $\mu$ ), while total SD was denoted as $\Sigma$. 


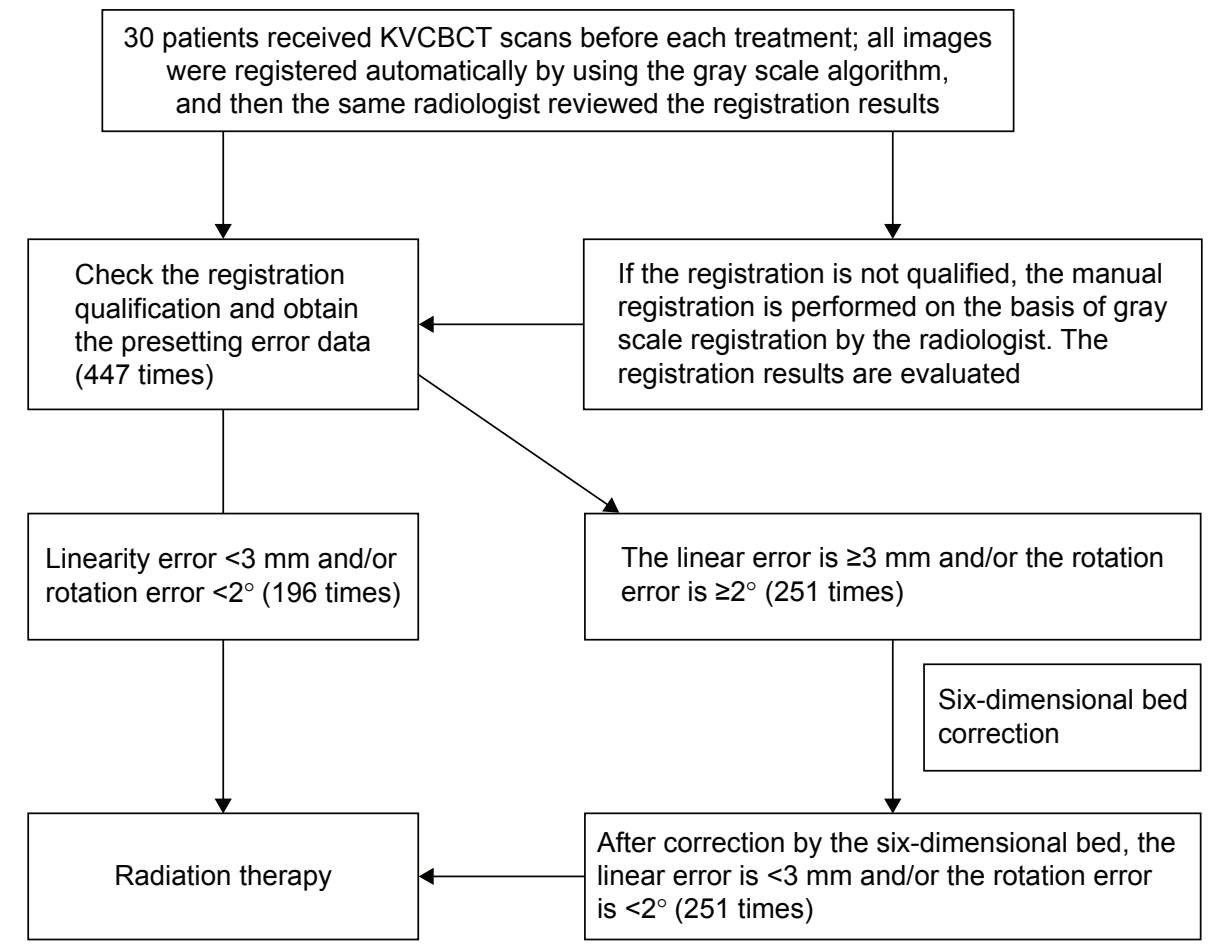

Figure I The IGRT protocol of the study.

Note: The enrolled patients were undertaken CBCT scans for registration before each treatment, and further corrections were applied if they were required as the flowchart. Abbreviations: CBCT, cone beam computed tomography; IGRT, image-guided radiotherapy; KVCBCT, kilovoltage cone beam computed tomography.

Total random error was denoted as $\delta$, which is the square root of the average value of the random errors in all patients. ${ }^{5}$ The corrected $\mathrm{M}_{\mathrm{PTV}}$ was calculated according to the formula for CTV-to-PTV margins: $\mathrm{M}_{\mathrm{PTV}}=2.5 \Sigma+0.7 \delta$.

\section{Statistical analysis}

Data were analyzed by statistical analysis software SPSS 11.5. Pre- and post-correction data were compared using paired $t$-test. $P<0.05$ was considered statistically significant.

\section{Results}

1. Total positioning errors: The last KVCBCT images of three patients were not registered because they did not complete the full-dose radiotherapy. Therefore, a total of $447 \mathrm{KVCBCT}$ images were acquired from 30 patients through KVCBCT scanning before each treatment, in which 196 images were found to have translational errors $<3 \mathrm{~mm}$ in three directions and rotational errors $<2^{\circ}$. Hence, no correction was required. The other 251 images exceeded the aforementioned range and required correction. This was obtained through the $6^{\circ}$ robotic patient positioning system.

2. The mean and standard deviation of translational errors in three dimensions and rotational errors for each patient before correction are shown in Table 1. Corrected results are shown in Table 2.
3. The mean of the uncorrected translational errors Lx, Ly and $\mathrm{Lz}$ in the 251 positioning images were $0.057 \pm$ $0.206,-0.095 \pm 0.401$ and $-0.112 \pm 0.259 \mathrm{~cm}$, respectively. After correction, the values were $-0.015 \pm 0.080,-0.029 \pm$ 0.072 and $-0.055 \pm 0.069 \mathrm{~cm}$, respectively. Through comparison using paired $t$-test, it was found that differences in errors in the $\mathrm{X}, \mathrm{Y}$ and $\mathrm{Z}$ axes before and after correction were statistically significant $(t=4.59,-2.10$ and -2.94 ; $P=0.000,0.037$ and 0.004). Among rotational errors $\mathrm{Rx}$, Ry and Rz, only Rx had a significant difference before and after correction ( $P=0.044,0.645$ and 0.128; Table 3 ).

4. In the X, Y and Z axes, the calculated CTV-to-PTV margins, $\mathrm{M}_{\mathrm{PTV}}$, before and after correction were $0.61,0.78$ and $0.41 \mathrm{~cm}$, respectively, and $0.17,0.12$ and $0.17 \mathrm{~cm}$, respectively. The margin differences of before and after correction were $0.44,0.66$, and $0.24 \mathrm{~cm}$, respectively, corresponding to $72 \%, 85 \%$ and $56 \%$ of the margins before correction, respectively (Table 4).

\section{Discussion}

Determining a method for reducing positioning errors in radiotherapy and determining how to reduce the influence of positioning errors on radiotherapy have become the focus of studies and have also been a challenge for doctors, radiation therapists and technicians in conducting studies of cancer 
Table I System and random errors in three dimensions and rotational directions for 30 patients before correction

\begin{tabular}{|c|c|c|c|c|c|c|}
\hline \multirow[t]{2}{*}{ ID } & \multirow{2}{*}{$\frac{\mathbf{L x}}{\overline{\mathbf{X}} \pm \text { SD }}$} & \multirow{2}{*}{$\frac{\text { Ly }}{\overline{\mathbf{x}} \pm \mathbf{S D}}$} & \multirow{2}{*}{$\frac{\mathbf{L z}}{\overline{\mathbf{X}} \pm \mathbf{S D}}$} & \multirow{2}{*}{$\begin{array}{l}\mathbf{R x} \\
\overline{\mathbf{X}} \pm \mathbf{S D}\end{array}$} & \multirow{2}{*}{$\frac{\text { Ry }}{\overline{\mathbf{x}} \pm \text { SD }}$} & \multirow{2}{*}{$\frac{\mathbf{R z}}{\overline{\mathbf{X}} \pm \mathbf{S D}}$} \\
\hline & & & & & & \\
\hline I & $-0.08 \pm 0.10$ & $-0.04 \pm 0.18$ & $-0.05 \pm 0.17$ & $0.01 \pm 0.53$ & $0.96 \pm 0.38$ & $0.04 \pm 0.43$ \\
\hline 2 & $0.22 \pm 0.08$ & $-0.56 \pm 0.23$ & $0.03 \pm 0.21$ & $1.50 \pm 0.69$ & $0.07 \pm 0.5 \mathrm{I}$ & $0.99 \pm 0.72$ \\
\hline 3 & $0.06 \pm 0.11$ & $-0.30 \pm 0.17$ & $-0.23 \pm 0.28$ & $0.4 I \pm 0.65$ & $-0.17 \pm 0.44$ & $0.60 \pm 0.25$ \\
\hline 4 & $0.04 \pm 0.07$ & $-0.28 \pm 0.24$ & $0.12 \pm 0.19$ & $2.77 \pm 0.93$ & $0.01 \pm 0.38$ & $-0.26 \pm 0.34$ \\
\hline 5 & $0.4 I \pm 0.13$ & $-0.14 \pm 0.38$ & $0.00 \pm 0.18$ & $-0.29 \pm 0.90$ & $-0.80 \pm 1.13$ & $-1.59 \pm 1.00$ \\
\hline 6 & $0.07 \pm 0.13$ & $-0.73 \pm 0.17$ & $-0.15 \pm 0.07$ & $2.29 \pm 0.30$ & $0.04 \pm 0.66$ & $-0.3 I \pm 0.27$ \\
\hline 7 & $-0.56 \pm 0.18$ & $0.23 \pm 0.28$ & $-0.12 \pm 0.18$ & $-1.92 \pm 1.08$ & $0.47 \pm 0.42$ & $0.04 \pm 1.01$ \\
\hline 8 & $0.15 \pm 0.14$ & $-0.04 \pm 0.29$ & $0.05 \pm 0.22$ & $1.38 \pm 1.26$ & $0.42 \pm 0.88$ & $-0.18 \pm 1.05$ \\
\hline 9 & $0.18 \pm 0.11$ & $-0.16 \pm 0.28$ & $-0.09 \pm 0.12$ & $-0.68 \pm 0.96$ & $-0.46 \pm 0.45$ & $-0.06 \pm 1.06$ \\
\hline 10 & $0.04 \pm 0.18$ & $-0.0 I \pm 0.3 I$ & $-0.13 \pm 0.31$ & $0.75 \pm 0.42$ & $-0.06 \pm 0.66$ & $-0.4 I \pm 0.42$ \\
\hline II & $0.16 \pm 0.18$ & $-0.14 \pm 0.30$ & $-0.20 \pm 0.13$ & $0.68 \pm 0.39$ & $-0.16 \pm 0.69$ & $0.21 \pm 0.60$ \\
\hline 12 & $0.09 \pm 0.24$ & $-0.09 \pm 0.22$ & $0.11 \pm 0.27$ & $-1.29 \pm 0.86$ & $0.8 I \pm 0.96$ & $0.22 \pm 0.83$ \\
\hline 13 & $-0.03 \pm 0.09$ & $-0.12 \pm 0.26$ & $0.06 \pm 0.23$ & $0.87 \pm 0.37$ & $0.15 \pm 0.48$ & $-0.38 \pm 0.50$ \\
\hline 14 & $0.12 \pm 0.12$ & $0.0 \mathrm{I} \pm 0.27$ & $-0.19 \pm 0.12$ & $0.04 \pm 0.52$ & $0.00 \pm 0.58$ & $0.5 I \pm 0.80$ \\
\hline 15 & $0.03 \pm 0.17$ & $0.07 \pm 0.22$ & $-0.21 \pm 0.15$ & $0.11 \pm 0.43$ & $0.02 \pm 0.74$ & $-0.14 \pm 0.5 \mathrm{I}$ \\
\hline 16 & $0.02 \pm 0.16$ & $0.19 \pm 0.27$ & $-0.13 \pm 0.17$ & $-0.91 \pm 0.84$ & $-0.46 \pm 0.45$ & $-0.72 \pm 0.57$ \\
\hline 17 & $0.00 \pm 0.13$ & $0.15 \pm 0.21$ & $-0.20 \pm 0.20$ & $-0.36 \pm 1.03$ & $0.81 \pm 0.62$ & $0.01 \pm 0.74$ \\
\hline 18 & $-0.14 \pm 0.13$ & $0.08 \pm 0.20$ & $-0.06 \pm 0.16$ & $1.27 \pm 1.04$ & $0.62 \pm 0.67$ & $-0.62 \pm 0.57$ \\
\hline 19 & $-0.22 \pm 0.30$ & $0.04 \pm 0.28$ & $0.01 \pm 0.12$ & $0.26 \pm 0.32$ & $0.28 \pm 0.92$ & $-0.94 \pm 0.68$ \\
\hline 20 & $0.10 \pm 0.16$ & $-0.06 \pm 0.20$ & $-0.05 \pm 0.17$ & $0.4 I \pm 0.65$ & $0.00 \pm 0.60$ & $0.52 \pm 0.90$ \\
\hline 21 & $0.03 \pm 0.12$ & $0.0 \mathrm{I} \pm 0.28$ & $-0.23 \pm 0.18$ & $0.87 \pm 0.36$ & $-0.46 \pm 0.45$ & $-0.06 \pm 1.06$ \\
\hline 22 & $0.00 \pm 0.30$ & $-0.16 \pm 0.24$ & $-0.20 \pm 0.22$ & $-0.29 \pm 0.90$ & $0.47 \pm 0.42$ & $0.98 \pm 0.72$ \\
\hline 23 & $0.42 \pm 0.08$ & $-0.01 \pm 0.18$ & $0.05 \pm 0.22$ & $0.03 \pm 0.52$ & $0.0 I \pm 0.38$ & $0.60 \pm 0.25$ \\
\hline 24 & $-0.16 \pm 0.24$ & $0.16 \pm 0.22$ & $0.12 \pm 0.19$ & $1.27 \pm 0.90$ & $-0.17 \pm 0.44$ & $-0.14 \pm 1.02$ \\
\hline 25 & $0.18 \pm 0.09$ & $-0.14 \pm 0.26$ & $-0.20 \pm 0.20$ & $2.29 \pm 0.30$ & $-0.16 \pm 0.69$ & $-0.26 \pm 0.34$ \\
\hline 26 & $0.22 \pm 0.18$ & $0.15 \pm 0.28$ & $-0.13 \pm 0.17$ & $-0.91 \pm 0.92$ & $0.07 \pm 0.48$ & $0.21 \pm 0.60$ \\
\hline 27 & $0.04 \pm 0.13$ & $-0.04 \pm 0.28$ & $0.03 \pm 0.21$ & $-0.36 \pm 1.00$ & $0.42 \pm 0.60$ & $0.60 \pm 0.25$ \\
\hline 28 & $0.18 \pm 0.24$ & $-0.12 \pm 0.29$ & $0.00 \pm 0.19$ & $0.11 \pm 0.43$ & $-0.56 \pm 0.92$ & $-0.62 \pm 0.57$ \\
\hline 29 & $-0.04 \pm 0.08$ & $-0.14 \pm 0.19$ & $-0.15 \pm 0.07$ & $1.32 \pm 1.26$ & $0.8 I \pm 0.62$ & $0.04 \pm 0.48$ \\
\hline 30 & $0.22 \pm 0.30$ & $-0.22 \pm 0.17$ & $-0.19 \pm 0.12$ & $0.04 \pm 0.52$ & $0.96 \pm 0.38$ & $-0.72 \pm 0.48$ \\
\hline
\end{tabular}

Notes: $\bar{x}$ denotes the average value of all positioning errors for each patient. Lx, Ly and Lz denote translational positioning errors in the $\mathrm{X}, \mathrm{Y}$ and $\mathrm{Z}$ axes, respectively. $\mathrm{Rx}$, Ry and $\mathrm{Rz}$ denote rotational errors with central axes located at the $\mathrm{X}, \mathrm{Y}$ and $\mathrm{Z}$ axes, respectively.

radiotherapy. To compensate the effects of positioning errors on the dose of radiotherapy, radiotherapy doctors must make PTV by expanding certain margins based on CTV. If the positioning errors are large, larger expanding margins can guarantee that the CTV of the radiotherapy can acquire an adequate prescription dose. However, larger expanding margins can bring greater radiation damage to normal tissues and organs and also limit the increase in dosage in PTV. ${ }^{6}$ To effectively reduce positioning errors in stepwise radiotherapy, a study revealed that thermoplastic film somatic fixation was more accurate than other fixation methods. ${ }^{7}$ At the same time, to more accurately measure the positioning errors, for both accurately measuring positioning errors and reducing damage to normal tissues, cone beam computed tomography (CBCT) is superior to the electronic portal imaging device (EPID) ${ }^{8,9}$ According to the abovementioned research results, this study was designed to investigate the difference in position errors before and after correction and its impact on PTV margins when patients were fixed by thermoplastic film, and positioning errors were measured by CBCT.

First, many studies have revealed that in the implementation of radiotherapy, positioning errors vary in different translational directions in different batches of radiotherapy. ${ }^{10-13}$ Differences in positioning errors were most significant in the $\mathrm{Y}$ and $\mathrm{Z}$ axes among the three linear directions in all these studies. Khosa et al ${ }^{12}$ reported that regardless of whether the reference was an implanted marker or bone marker, displacement was most significant in the direction of the $\mathrm{Y}$ axis, followed by the direction of the $\mathrm{Z}$ axis. Osei et $\mathrm{a}^{13}$ reported that when an implanted marker was set as reference, displacement in the $\mathrm{Z}$ axis was the most significant, followed by that in the $\mathrm{Y}$ axis. Furthermore, when the reference was a bone marker, displacement was most significant in the $\mathrm{Y}$ axis, followed by the $\mathrm{Z}$ axis. In this study, patients were 
Table 2 System and random errors in three dimensions and rotational directions for 30 patients after correction

\begin{tabular}{|c|c|c|c|c|c|c|}
\hline \multirow[t]{2}{*}{ ID } & $\mathbf{L x}$ & Ly & $\mathbf{L z}$ & $\mathbf{R x}$ & Ry & $\mathbf{R z}$ \\
\hline & $\overline{\mathbf{x}} \pm \mathbf{S D}$ & $\overline{\mathbf{x}} \pm \mathbf{S D}$ & $\overline{\mathbf{x}} \pm \mathbf{S D}$ & $\overline{\mathbf{x}} \pm \mathbf{S D}$ & $\overline{\mathbf{x}} \pm \mathbf{S D}$ & $\overline{\mathbf{x}} \pm \mathbf{S D}$ \\
\hline I & $-0.07 \pm 0.04$ & $-0.0 I \pm 0.04$ & $-0.04 \pm 0.04$ & $0.12 \pm 0.13$ & $0.22 \pm 0.28$ & $-0.04 \pm 0.09$ \\
\hline 2 & $0.03 \pm 0.07$ & $-0.06 \pm 0.11$ & $-0.05 \pm 0.06$ & $0.42 \pm 0.72$ & $0.21 \pm 0.37$ & $0.39 \pm 0.63$ \\
\hline 3 & $-0.07 \pm 0.15$ & $-0.05 \pm 0.03$ & $-0.04 \pm 0.03$ & $-0.14 \pm 0.24$ & $0.07 \pm 0.30$ & $0.09 \pm 0.20$ \\
\hline 4 & $-0.03 \pm 0.04$ & $-0.06 \pm 0.04$ & $-0.05 \pm 0.02$ & $1.02 \pm 1.00$ & $0.07 \pm 0.08$ & $0.05 \pm 0.27$ \\
\hline 5 & $-0.03 \pm 0.09$ & $-0.02 \pm 0.10$ & $-0.05 \pm 0.06$ & $-0.26 \pm 0.61$ & $-0.7 I \pm 0.26$ & $-0.44 \pm 0.98$ \\
\hline 6 & $-0.05 \pm 0.05$ & $-0.08 \pm 0.06$ & $-0.09 \pm 0.07$ & $0.90 \pm 0.68$ & $0.03 \pm 0.74$ & $0.15 \pm 0.37$ \\
\hline 7 & $0.00 \pm 0.06$ & $-0.02 \pm 0.07$ & $-0.10 \pm 0.05$ & $-1.35 \pm 1.10$ & $0.65 \pm 0.17$ & $-0.27 \pm 0.74$ \\
\hline 8 & $0.03 \pm 0.03$ & $-0.04 \pm 0.08$ & $-0.02 \pm 0.03$ & $0.23 \pm 0.29$ & $-0.23 \pm 0.23$ & $0.03 \pm 0.92$ \\
\hline 9 & $0.15 \pm 0.12$ & $-0.06 \pm 0.09$ & $-0.05 \pm 0.05$ & $-0.82 \pm 0.73$ & $-0.38 \pm 0.55$ & $0.22 \pm 0.72$ \\
\hline 10 & $0.01 \pm 0.10$ & $-0.04 \pm 0.04$ & $-0.02 \pm 0.03$ & $-0.14 \pm 0.28$ & $-0.08 \pm 0.25$ & $-0.05 \pm 0.26$ \\
\hline 11 & $0.0 \mathrm{I} \pm 0.04$ & $0.01 \pm 0.05$ & $-0.12 \pm 0.09$ & $0.63 \pm 0.29$ & $-0.12 \pm 0.67$ & $0.35 \pm 0.69$ \\
\hline 12 & $-0.06 \pm 0.10$ & $-0.03 \pm 0.07$ & $0.00 \pm 0.09$ & $0.16 \pm 0.68$ & $0.15 \pm 0.83$ & $0.16 \pm 0.42$ \\
\hline 13 & $0.01 \pm 0.07$ & $0.00 \pm 0.05$ & $-0.0 \mathrm{I} \pm 0.05$ & $0.74 \pm 0.5 \mathrm{I}$ & $0.29 \pm 0.55$ & $-0.43 \pm 0.48$ \\
\hline 14 & $-0.07 \pm 0.05$ & $-0.02 \pm 0.13$ & $-0.03 \pm 0.03$ & $0.13 \pm 0.14$ & $0.18 \pm 0.31$ & $0.15 \pm 0.22$ \\
\hline 15 & $-0.02 \pm 0.07$ & $-0.04 \pm 0.06$ & $-0.09 \pm 0.06$ & $0.18 \pm 0.32$ & $-0.13 \pm 0.52$ & $-0.11 \pm 0.35$ \\
\hline 16 & $0.01 \pm 0.03$ & $0.00 \pm 0.09$ & $-0.04 \pm 0.05$ & $-0.84 \pm 0.74$ & $-0.74 \pm 0.50$ & $-0.60 \pm 0.55$ \\
\hline 17 & $-0.01 \pm 0.08$ & $0.01 \pm 0.07$ & $-0.15 \pm 0.08$ & $0.12 \pm 0.82$ & $0.87 \pm 0.6 \mathrm{I}$ & $-0.13 \pm 0.76$ \\
\hline 18 & $-0.07 \pm 0.08$ & $-0.05 \pm 0.03$ & $-0.05 \pm 0.05$ & $0.29 \pm 0.77$ & $-0.24 \pm 0.54$ & $-0.11 \pm 0.43$ \\
\hline 19 & $-0.03 \pm 0.05$ & $-0.03 \pm 0.02$ & $-0.06 \pm 0.07$ & $0.27 \pm 0.23$ & $0.33 \pm 1.29$ & $-1.03 \pm 0.65$ \\
\hline 20 & $0.02 \pm 0.04$ & $-0.04 \pm 0.05$ & $-0.01 \pm 0.02$ & $-0.16 \pm 0.28$ & $0.72 \pm 0.74$ & $0.53 \pm 0.42$ \\
\hline 21 & $0.15 \pm 0.08$ & $-0.01 \pm 0.09$ & $-0.10 \pm 0.07$ & $0.29 \pm 0.62$ & $0.82 \pm 1.00$ & $-1.00 \pm 0.32$ \\
\hline 22 & $0.01 \pm 0.03$ & $0.05 \pm 0.11$ & $0.01 \pm 0.09$ & $0.76 \pm 0.54$ & $-0.52 \pm 0.50$ & $-0.58 \pm 0.22$ \\
\hline 23 & $-0.15 \pm 0.01$ & $-0.06 \pm 0.07$ & $0.00 \pm 0.02$ & $-0.10 \pm 0.72$ & $0.64 \pm 0.68$ & $0.08 \pm 0.78$ \\
\hline 24 & $-0.07 \pm 0.04$ & $0.05 \pm 0.09$ & $-0.04 \pm 0.04$ & $0.09 \pm 0.75$ & $0.04 \pm 0.30$ & $-0.55 \pm 0.03$ \\
\hline 25 & $-0.02 \pm 0.06$ & $-0.08 \pm 0.05$ & $-0.06 \pm 0.02$ & $0.22 \pm 0.5 \mathrm{I}$ & $-0.56 \pm 0.54$ & $-0.09 \pm 0.34$ \\
\hline 26 & $0.03 \pm 0.08$ & $0.00 \pm 0.09$ & $-0.04 \pm 0.07$ & $0.08 \pm 0.79$ & $0.75 \pm 0.31$ & $0.28 \pm 0.69$ \\
\hline 27 & $-0.05 \pm 0.06$ & $-0.02 \pm 0.07$ & $0.00 \pm 0.04$ & $0.82 \pm 0.19$ & $0.94 \pm 0.03$ & $-0.76 \pm 0.34$ \\
\hline 28 & $0.02 \pm 0.02$ & $0.04 \pm 0.09$ & $-0.09 \pm 0.05$ & $-0.68 \pm 0.23$ & $0.33 \pm 0.55$ & $-0.09 \pm 0.03$ \\
\hline 29 & $-0.01 \pm 0.06$ & $-0.03 \pm 0.11$ & $-0.04 \pm 0.02$ & $0.23 \pm 1.10$ & $-0.24 \pm 0.56$ & $0.74 \pm 0.28$ \\
\hline 30 & $-0.05 \pm 0.03$ & $-0.05 \pm 0.07$ & $-0.02 \pm 0.07$ & $-0.26 \pm 0.84$ & $0.08 \pm 1.10$ & $-1.00 \pm 0.35$ \\
\hline
\end{tabular}

Notes: $\bar{x}$ denotes the average value of all positioning errors for each patient. $L x$, Ly and $L z$ denote translational positioning errors in the $\mathrm{X}, \mathrm{Y}$ and $\mathrm{Z}$ axes, respectively. $\mathrm{Rx}$, Ry and $\mathrm{Rz}$ denote rotational errors with central axes located at the $\mathrm{X}, \mathrm{Y}$ and $\mathrm{Z}$ axes, respectively.

fixed with thermoplastic film in the supine position; and positioning errors before correction in the $\mathrm{X}, \mathrm{Y}$ and $\mathrm{Z}$ axes were $0.057 \pm 0.206,-0.095 \pm 0.401$ and $-0.112 \pm 0.259 \mathrm{~cm}$, respectively. Displacements in the directions of $\mathrm{Y}$ and $\mathrm{Z}$ axes were the most significant, which were consistent with the results of the abovementioned studies. The main reason why the displacement in the $\mathrm{Y}$ axis was most significant was that the stability of the somatic thermoplastic film fixation in the head-foot direction was the worst, and other reasons were the influence from the filled bladder above. The reason that the displacement in the $\mathrm{Z}$ axis was significant may be that the influence of the filled rectum was

Table 3 Comparison of $25 \mathrm{I}$ times of six-direction positioning image errors over range before and after correction

\begin{tabular}{|c|c|c|c|c|c|}
\hline \multirow{3}{*}{$\begin{array}{l}\text { Correction } \\
\text { directions }\end{array}$} & \multirow[t]{3}{*}{ Times } & \multirow{3}{*}{$\begin{array}{l}\text { Before } \\
\text { correction } \\
\overline{\mathbf{X}} \pm \text { SD } \\
\end{array}$} & \multirow{3}{*}{$\begin{array}{l}\text { After } \\
\text { correction } \\
\overline{\overline{\mathbf{X}} \pm \text { SD }}\end{array}$} & \multicolumn{2}{|c|}{ Paired $t$-test } \\
\hline & & & & & \\
\hline & & & & $T$ value & $P$-value \\
\hline Lx & 251 & $0.0572 \pm 0.2062$ & $-0.0149 \pm 0.0796$ & 4.594 & 0.000 \\
\hline Ly & 251 & $-0.0952 \pm 0.4015$ & $-0.0294 \pm 0.0720$ & -2.099 & 0.037 \\
\hline Lz & 251 & $-0.1116 \pm 0.2590$ & $-0.0545 \pm 0.0686$ & -2.935 & 0.004 \\
\hline $\mathrm{Rx}$ & 251 & $0.3114 \pm 1.3937$ & $0.132 I \pm 0.7473$ & 2.032 & 0.044 \\
\hline Ry & 251 & $0.1057 \pm 0.8748$ & $0.0767 \pm 0.6039$ & 0.462 & 0.645 \\
\hline $\mathrm{Rz}$ & 251 & $-0.1390 \pm 0.8205$ & $0.0572 \pm 0.5804$ & -1.532 & 0.128 \\
\hline
\end{tabular}

Notes: $\bar{x}$ denotes the average value of all positioning errors for each patient. Lx, Ly and Lz denote translational positioning errors in the $\mathrm{X}, \mathrm{Y}$ and $\mathrm{Z}$ axes, respectively. $\mathrm{Rx}$, Ry and $\mathrm{Rz}$ denote rotational errors with central axes located at the $\mathrm{X}, \mathrm{Y}$ and $\mathrm{Z}$ axes, respectively. 
Table 4 Comparison of the calculated margins before and after correction

\begin{tabular}{|c|c|c|c|c|c|c|c|c|}
\hline \multirow[t]{3}{*}{ Directions } & \multicolumn{3}{|c|}{ Before correction } & \multicolumn{3}{|c|}{ After correction } & \multicolumn{2}{|c|}{$\begin{array}{l}\text { Expanding margins front } \\
\text { and back }\end{array}$} \\
\hline & $\begin{array}{l}\text { System } \\
\text { error }\end{array}$ & $\begin{array}{l}\text { Random } \\
\text { error }\end{array}$ & $\begin{array}{l}\text { Expanding } \\
\text { margins }\end{array}$ & $\begin{array}{l}\text { System } \\
\text { error }\end{array}$ & $\begin{array}{l}\text { Random } \\
\text { error }\end{array}$ & $\begin{array}{l}\text { Expanding } \\
\text { margins }\end{array}$ & $D$ value & Percentage \\
\hline & $\mu \pm \Sigma$ & $\delta$ & $\mathbf{M}_{\mathrm{PTV}}$ & $\mu \pm \Sigma$ & $\delta$ & $M_{\mathrm{PTV}}$ & & \\
\hline $\mathrm{X}$ axis & $0.03 \pm 0.20$ & 0.15 & 0.61 & $0.00 \pm 0.05$ & 0.07 & 0.17 & 0.44 & 72 \\
\hline$Y$ axis & $-0.10 \pm 0.24$ & 0.26 & 0.78 & $-0.26 \pm 0.03$ & 0.07 & 0.12 & 0.66 & 85 \\
\hline$Z$ axis & $-0.07 \pm 0.11$ & 0.19 & 0.41 & $-0.05 \pm 0.05$ & 0.06 & 0.17 & 0.24 & 56 \\
\hline
\end{tabular}

Notes: Translation unit in $\mathrm{cm}$; expanding margins, $\mathrm{M}_{\mathrm{PTV}}=2.5 \Sigma+0.7 \delta$. The $D$ values show the difference of expanding margins of before correction over after correction. Abbreviation: $M_{\text {PTV }}$, planning target volume margins.

significant. Previous related studies have also considered that the filled bladder and rectum were the main factors for positioning errors. ${ }^{4,14}$ After correction by the $6^{\circ}$ robotic patient positioning system, the positioning errors in the $\mathrm{X}, \mathrm{Y}$ and $\mathrm{Z}$ axes were $-0.015 \pm 0.080,-0.029 \pm 0.072$ and $-0.055 \pm 0.069$, respectively, which were significantly different from those before correction ( $P=0.000,0.037$ and 0.004 , respectively).

Second, in addition to linear displacement, the rotational error of the prostate is inevitable in the process of radiotherapy. Tehrani et a ${ }^{15}$ reported that based on the iterative closest point (ICP) algorithm, rotational errors of the prostate, in which the central axes were the $\mathrm{X}, \mathrm{Y}$ and $\mathrm{Z}$ axes, were $2.3^{\circ}, 0.89^{\circ}$ and $0.72^{\circ}$, respectively. Graf et a $1^{16}$ reported that the rotational errors of these three axes are $-0.01^{\circ} \pm 3.95^{\circ}$, $0.09^{\circ} \pm 2.01^{\circ}$ and $0.52^{\circ} \pm 2.30^{\circ}$, respectively.

The aforementioned two studies on rotational error revealed that the rotational error with the central axis located at the $\mathrm{X}$ axis was the most significant among the three axis directions. In this study, rotational errors in these three axis directions were $0.31^{\circ} \pm 1.39^{\circ}, 0.11^{\circ} \pm 0.87^{\circ}$ and $-0.14^{\circ} \pm 0.82^{\circ}$, respectively. These were consistent with the results of the previous two studies, in which the rotational error in the $\mathrm{X}$ axis was the most significant. The reasons remain possibly correlated with the filling status of the rectum and bladder. In this study, rotational errors in these three axes after correction by the $6^{\circ}$ robotic patient positioning system were $0.13^{\circ} \pm 0.75^{\circ}, 0.78^{\circ} \pm 0.60^{\circ}$ and $-0.06^{\circ} \pm 0.58^{\circ}$, respectively, and only the reduction rate in the $\mathrm{X}$ axis was statistically significant compared with those before correction $(P=0.044)$. The reason for this result is that the rotational error in the $\mathrm{X}$ axis is more prone to influence factors for translational errors, and the significant differences in these two kinds of errors may be related to the filling status of the bladder and rectum. Results of this analysis can be further verified by evaluating the correlation between the filling status of the rectum and bladder and positioning errors.

Related studies revealed that in intensity-modulated radiotherapy for prostate cancer, PTV derived from even external expansion by $10 \mathrm{~mm}$ on the basis of CTV was inferior to PTV that formed from the reduction of margins after IGRT correction in the following two aspects: target motion sensitivity and reduction of irradiation dose on risk organs. ${ }^{17,18}$ Under the condition of IGRT guided by CBCT, the results of this study revealed that the correction of overstandard displacement using the $6^{\circ}$ robotic patient positioning system could effectively reduce translational errors. To further discuss the influence of positioning error reduction on margins, we calculated PTV based on the formula: $\mathrm{M}_{\mathrm{PTV}}=2.5 \Sigma+0.7 \delta$, which was proposed by van Herk et al. ${ }^{4}$ This formula is based on the cumulative dose distribution and minimum CTV cumulative dose in population-based patients, which avoids the interference of tumor diameter, considers the influence of both system error and random error on the dose and guarantees that the minimum cumulative dose of CTV can reach at least $95 \%$ of the prescribed dose in $90 \%$ of patients. Hence, it was calculated that before correction, $\mathrm{M}_{\mathrm{PTV}}$ values in the $\mathrm{X}, \mathrm{Y}$ and $\mathrm{Z}$ directions were $0.61,0.78$ and $0.41 \mathrm{~cm}$, respectively. Furthermore, after correction, $\mathrm{M}_{\mathrm{PTV}}$ values in the three directions were $0.17,0.12$ and $0.17 \mathrm{~cm}$, respectively. Therefore, it is obvious that the $\mathrm{M}_{\mathrm{PTV}}$ margins were reduced significantly from the difference of before and after corrections, 0.44, 0.66 and $0.24 \mathrm{~cm}$, respectively; and the reduction rates were $72 \%$, $85 \%$ and $56 \%$, respectively. The number of studies in which prostate cancer PTV margins were calculated based on this formula is large. Furthermore, a number of studies revealed that before positioning errors were corrected in the $\mathrm{X}, \mathrm{Y}$ and $\mathrm{Z}$ axes, $\mathrm{M}_{\text {PTV }}$ values were $0.14-0.93,0.40-1.2$ and $0.47-1.05 \mathrm{~cm}$, respectively. ${ }^{19-21}$ Studies conducted by Skarsgard et a ${ }^{22}$ and Rudat et $\mathrm{al}^{23}$ revealed that PTV margins were significantly reduced through image guidance and positioning error correction, even though the margins in every day IGRT did not significantly decline. In the former study, $\mathrm{M}_{\mathrm{PTV}}$ values before and after error correction in the $\mathrm{X}, \mathrm{Y}$ and $\mathrm{Z}$ axes were $0.57,0.79$ and $0.77 \mathrm{~cm}$ and $0.36,0.37,0.37 \mathrm{~cm}$, respectively. In the latter study, error correction was conducted every 2 days, and $\mathrm{M}_{\text {PTV }}$ values before and after correction in the $\mathrm{X}, \mathrm{Y}$ and $\mathrm{Z}$ axes were 
$0.82,1.14$ and $1.15 \mathrm{~cm}$ and $0.41,0.81$ and $0.66 \mathrm{~cm}$, respectively. The results of the aforementioned studies revealed that although the same formula was used, the conditions of different radiotherapy institutions were different, systemic positioning errors were different and the final calculated $\mathrm{M}_{\text {PTV }}$ also had significant differences. The consistency is that PTV margins could be reduced by the correction of positioning errors. In summary, in the course of radiotherapy, the conditions in different institutions differ, and systemic positioning errors and PTV margins also differ.

\section{Conclusion}

To improve the accuracy of radiotherapy and reduce the irradiated volume of normal tissues and risk organs as far as possible, reasonable PTV margins should differ based on different radiotherapy conditions in different agencies. In the present study, the PTV margins obtained through calculating with the data obtained before and after correction of positioning error using IGRT, which was based on the formula: $\mathrm{M}_{\mathrm{PTV}}=2.5 \Sigma+0.7 \delta$, were significantly different. After correction, the PTV margins decreased by $72 \%, 85 \%$ and $56 \%$ in the three linear directions of $\mathrm{X}, \mathrm{Y}$ and $\mathrm{Z}$, respectively. But these values are only analog values, which require further verification online. In this study, the calculated PTV margins were based on positioning systematic errors, which are just simulation values. Hence, further online verifications are required.

\section{Disclosure}

The authors report no conflicts of interest in this work.

\section{References}

1. Nijkamp J, Pos FJ, Nuver TT, et al. Adaptive radiotherapy for prostate cancer using kilovoltage cone-beam computed tomography: first clinical results. Int J Radiat Oncol Biol Phys. 2008;70(1):75-82.

2. Wong JR, Gao Z, Uematsu M, et al. Interfractional prostate shifts: review of 1870 computed tomography (CT) scans obtained during image-guided radiotherapy using CT-on-rails for the treatment of prostate cancer. Int J Radiat Oncol Biol Phys. 2008;72(5):1396-1401.

3. Palombarini M, Mengoli S, Fantazzini P, Cadioli C, Degli Esposti C, Frezza GP. Analysis of inter-fraction setup errors and organ motion by daily kilovoltage cone beam computed tomography in intensity modulated radiotherapy of prostate cancer. Radiat Oncol. 2012;7:56.

4. van Herk M, Remeijer P, Rasch C, Lebesque JV. The probability of correct target dosage: dose-population histograms for deriving treatment margins in radiotherapy. Int J Radiat Oneol Biol Phys. 2000;47(4):1121-1135.

5. van Herk M. Errors and margins in radiotherapy. Semin Rodiat Oncol.2004; 14(1):52-64.

6. Hoskin P. External Beam Therapy. 2nd ed. Oxford: Oxford University Press; 2012.
7. White P, Yee CK, Shan LC, Chung LW, Man NH, Cheung YS A comparison of two systems of patient immobilization for prostate radiotherapy. Radiat Oncol. 2014;9:29.

8. Ost P, De Gersem W, De Potter B, Fonteyne V, De Neve W, De Meerleer G. A comparison of the acute toxicity profile between two-dimensional and three-dimensional image-guided radiotherapy for postoperative prostate cancer. Clin Oncol. 2011;23(5):344-349.

9. Ung NM, Wee L, Hackett SL, Jones A, Lim TS, Harper CS. Comparison of low-dose, half-rotation, cone-beam CT with electronic portal imaging device for registration of fiducial markers during prostate radiotherapy. J Appl Clin Med Phys. 2013;14(4):4249.

10. Bylund KC, Bayouth JE, Smith MC, Hass AC, Bhatia SK, Buatti JM. Analysis of interfraction prostate motion using megavoltage cone beam computed tomography. Int J Radiat Oncol Biol Phys. 2008; 72(3):949-956.

11. Cendales R, Torres F, Arbelaez J, Gaitan A, Vasquez J, Bobadilla I. Displacements of fiducial markers in patients with prostate cancer treated with image guided radiotherapy: a single-institution descriptive study. Rep Pract Oncol Radiother. 2014;20(1):38-42.

12. Khosa R, Nangia S, Chufal KS, Ghosh D, Kaul R, Sharma L. Daily online localization using implanted fiducial markers and its impact on planning target volume for carcinoma prostate. J Cancer Res Ther. 2010; 6(2):172-178.

13. Osei EK, Jiang R, Barnett R, Fleming K, Panjwani D. Evaluation of daily online set-up errors and organ displacement uncertainty during conformal radiation treatment of the prostate. Br J Radiol. 2009;82(973): 49-61.

14. Ten Haken RK, Forman JD, Heimburger DK, et al. Treat-ment planning issues related to prostate movement in response to differential filling of the rectum and bladder. Int J Radiat Oncol Biol Phys. 1991; 20(6):1317-1324.

15. Tehrani JN, O’Brien RT, Poulsen PR, Keall P. Real-time estimation of prostate tumor rotation and translation with a $\mathrm{kV}$ imaging system based on an iterative closest point algorithm. Phys Med Biol. 2013;58(23):8517-8533.

16. Graf R, Boehmer D, Budach V, Wust P. Interfraction rotation of the prostate as evaluated by kilovoltage $\mathrm{X}$-ray fiducial marker imaging in intensity-modulated radiotherapy of localized prostate cancer. Med Dosim. 2012;37(4):396-400.

17. Góra J, Stock M, Lütgendorf-Caucig C, Georg D. Is there an advantage in designing adapted, patient-specific PTV margins in intensity modulated proton beam therapy for prostate cancer? Int J Radiat Oncol Biol Phys. 2013;85(3):881-888.

18. Pérez-Romasanta LA, Lozano-Martín E, Velasco-Jiménez J, et al. CTV to PTV margins for prostate irradiation. Three-dimensional quantitative assessment of interfraction uncertainties using portal imaging and serial CT scans. Clin Transl Oncol. 2009;11(9):615-621.

19. Kliton J, Agoston P, Major T, Polgár C. Patient positioning using inroom $\mathrm{kV} \mathrm{CT}$ for image-guided radiotherapy (IGRT) of prostate cancer. Magy Onkol. 2012;56(3):193-198.

20. Ikeda I, Mizowaki T, Sawada Y, et al. Assessment of interfractional prostate motion in patients immobilized in the prone position using a thermoplastic shell. J Radiat Res. 2014;55(1):168-174.

21. Kanakavelu N, Jebaseelan Samuel J. Determination of patient set-up error and optimal treatment margin for intensity modulated radiotherapy using image guidance system. J BUON. 2016;21(2):505-511.

22. Skarsgard D, Cadman P, El-Gayed A, et al. Planning target volume margins for prostate radiotherapy using daily electronic portal imaging and implanted fiducial markers. Radiat Oncol. 2010;5:52.

23. Rudat V, Nour A, Hammoud M, Alaradi A, Mohammed A. Imageguided intensity-modulated radiotherapy of prostate cancer: analysis of interfractional errors and acute toxicity. Strahlenther Onkol. 2016; 192(2):109-117. 


\section{Publish your work in this journal}

OncoTargets and Therapy is an international, peer-reviewed, open access journal focusing on the pathological basis of all cancers, potential targets for therapy and treatment protocols employed to improve the management of cancer patients. The journal also focuses on the impact of management programs and new therapeutic agents and protocols on

patient perspectives such as quality of life, adherence and satisfaction. The manuscript management system is completely online and includes a very quick and fair peer-review system, which is all easy to use. Visit http://www.dovepress.com/testimonials.php to read real quotes from published authors.

Submit your manuscript here: http://www.dovepress.com/oncotargets-and-therapy-journal 